\title{
Responses of reef fish communities to coral declines on the Great Barrier Reef
}

\author{
Alistair J. Cheal ${ }^{1, *}$, Shaun K. Wilson ${ }^{1,2,3}$, Michael J. Emslie ${ }^{1}$, Andrew M. Dolman¹, \\ Hugh Sweatman ${ }^{1}$
}

\author{
${ }^{1}$ Australian Institute of Marine Science, PMB No. 3, Townsville MC, Townsville, 4810 Queensland, Australia \\ ${ }^{2}$ School of Marine Science and Technology, University of Newcastle, Newcastle-upon-Tyne NE1 7RU, UK \\ ${ }^{3}$ ARC Centre of Excellence for Coral Reef Studies, James Cook University, Townsville, 4811 Queensland, Australia
}

\begin{abstract}
The functional roles of certain reef fishes are considered to facilitate recovery of reef ecosystems following coral mortality. Maintenance of high fish species diversity and associated functional diversity are thought to represent an 'ecological insurance' against ecosystem degradation. We examined responses of reef fish communities to varied levels of coral decline on 22 individual reefs of the Great Barrier Reef over an 11 yr period. Using 7 measures of species diversity, we found that fish diversity rarely decreased due to coral declines, even on 7 reefs that suffered massive coral losses (cover decreased by $>75 \%$ ). However, maintenance of fish diversity on those 7 reefs belied major changes in fish communities that involved increases in abundance of large herbivores and decreases in abundance of both coral-dependent fishes and species with no obvious dependence on coral. The magnitude of change in species abundances increased linearly with the magnitude of coral decline. While the proportion of species that increased or decreased in abundance varied considerably among reefs, 45 to $71 \%$ of fish species decreased in abundance on some reefs. Ecological function is related to abundance, so such decreases are likely to indicate reduced ecosystem function. Our results suggest that: (1) reef fish diversity may not be a reliable indicator of reef resilience and (2) predicted declines in coral cover due to global warming are likely to cause changes in the structure of reef fish communities, but the nature of these changes and associated capacity of reef fishes to assist ecosystem recovery will vary among reefs.
\end{abstract}

KEY WORDS: Diversity $\cdot$ Abundance $\cdot$ Community structure $\cdot$ Resilience $\cdot$ Climate change $\cdot$ Global warming $\cdot$ Herbivores

Resale or republication not permitted without written consent of the publisher

\section{INTRODUCTION}

The nature of relationships between reef fishes and corals has received increased attention since the unprecedented global declines in coral cover that occurred in 1998 due to coral bleaching (Wilkinson 2004). Bleaching events, where corals expel their symbiotic algae, are most commonly triggered by higher than average ocean temperatures (Wilkinson \& Souter 2008). Global warming is likely to increase average and maximum ocean temperatures even further (Wilkinson 2004), resulting in a higher frequency and intensity of bleaching events (Hoegh-Guldberg 2004) and tropical storms, another common cause of coral mortality (Sriver \& Huber 2007). Such predictions have contributed to warnings that $50 \%$ of the world's coral reefs are either under an imminent or longerterm threat of collapse (Wilkinson 2004).

What effect will such coral declines have on reef fishes that help support general ecosystem function through energy transfer, grazing and removal of sediment (Bellwood et al. 2004, Mumby et al. 2006, Munday et al. 2007), as well as providing great nutritional, social and economic benefits to associated human populations (Moberg \& Folke 1999)? Detrimental effects of coral loss on fish communities are restricted initially to fish species that depend on living corals for food or shelter, notably corallivorous chaeto- 
dontid fishes (Bouchon-Navaro et al. 1985, Pratchett et al. 2006, 2008, Wilson et al. 2006). In the longer term, abundances of other fish species without obvious coral associations may be adversely affected by coral mortality through suppression of settlement cues (Booth \& Beretta 2002, Jones et al. 2004) and reductions in reef topographic complexity (Jones \& Syms 1998, Pratchett et al. 2008).

Topographic complexity of reefs is often correlated with the diversity and abundance of reef fishes (Risk 1972, Sano et al. 1987, Syms \& Jones 2000); more complex habitat provides a greater range of living spaces and refugia, thus moderating major biotic factors such as competition and predation (Pratchett et al. 2008). Accordingly, disturbances that kill coral tissue but leave the hard skeleton intact (i.e. coral bleaching and outbreaks of crown-of-thorns starfish) are likely to have less impact on fish communities in the short term than disturbances that break up or remove whole coral colonies (i.e. tropical storms). However, subsequent erosion of coral skeletons without coral recruitment will gradually reduce topographic complexity and may have lagged detrimental effects on entire fish communities (Garpe et al. 2006). The structural complexity of the underlying substrate will also moderate effects of coral losses on reef fishes; highly rugose substrates may support diverse fish communities even if corals are removed, while flat substrates may not (Halford et al. 2004, Emslie et al. in press).

Analysis of 17 independent studies revealed that species richness of reef fishes typically declined within 3 yr of a loss of $>20 \%$ of coral cover, and abundances of $62 \%$ of species declined after coral losses of $>10 \%$ (Wilson et al. 2006). Longer-term studies (8 to $12 \mathrm{yr}$ ) of coral declines in Papua New Guinea (Jones et al. 2004), Tanzania (Garpe et al. 2006) and the Seychelles (Graham et al. 2006) have recorded dramatic declines in both reef fish diversity and abundance in a broad range of taxa. While short-term effects of coral mortality on reef fishes can be variable, these studies show that fish communities are likely to suffer long-term changes unless coral communities begin to recover.

The only 2 comparable long-term studies from the Great Barrier Reef (GBR), Australia, produced conflicting results. One showed widespread decreases in both fish diversity and abundance following major coral declines on contiguous reef slopes on 4 outer reefs (Halford et al. 2004). The second found no detectable changes in diversity or total abundance of cryptobenthic fishes on small coral bommies $\left(2 \mathrm{~m}^{3}\right)$ at 1 inshore reef 6 yr after major coral mortality, but there was a long-term shift in community structure, characterised by trophic simplification (Bellwood et al. 2006). High diversity is often assumed to indicate a resilient (Loreau et al. 2002) and healthy ecosystem, where re- silience is defined as the capacity to recover from disturbances and resist shifts to an alternative state. However, the results of Bellwood et al. (2006) suggest that maintenance of fish diversity does not necessarily confer resilience to fish communities, nor does it reflect the general ecosystem status. Maintenance of biodiversity may provide an 'ecological insurance' against general ecosystem degradation by enhancing stability and recovery potential (Hooper et al. 2005, Worm et al. 2006), but this assumes that certain species or functional groups are retained in sufficient numbers so that crucial ecological functions are sustained (Chapin et al. 2000, Folke et al. 2004). Widespread reductions in abundance of fish species without extinctions could result in a functionally depauperate community and reduced resilience of the reef ecosystem, even though fish diversity did not change.

While resilience of coral reef ecosystems to major disturbances has been documented (Sano 2000, Halford et al. 2004), many reef systems have shifted from coral to algal dominance and are perceived to be in a degraded state (Hughes et al. 2007). This change has been partly attributed to insufficient herbivory by reef fishes as a result of overfishing. A range of herbivorous fish taxa that graze upon algal turfs (i.e. species within the Acanthuridae and Scaridae) are likely to inhibit phase shifts to algal dominance following coral declines and enhance conditions for settlement of coral larvae (Bellwood et al. 2004, Hughes et al. 2007). Other 'nominal herbivores' that feed on detritus are often very abundant on shallow coral reefs (particularly the acanthurid Ctenochaetus spp.; Wilson et al. 2003), yet their role in preventing phase shifts is unclear, while the few species that actually consume fleshy macroalgae have the potential to reverse phase shifts (Pratchett et al. 2008). Coral mortality creates space for algae to colonize, but responses of fish herbivores to the increased algal supply have included increases, no change and decreases in abundance (Birkeland \& Lucas 1990, Wilson et al. 2006). In one case, abundance of herbivores increased immediately after a bleaching event, but then decreased markedly as habitat eroded (Garpe et al. 2006). Increases in herbivore abundance to exploit greater food availability are likely to reflect either migration (Wilson et al. 2006) or enhanced recruitment, the latter being contingent upon favourable oceanographic conditions for the fish larvae (Birkeland \& Lucas 1990).

We examined responses of reef fish communities to coral declines on the GBR over an $11 \mathrm{yr}$ period. Our study was conducted on contiguous reef slopes and incorporated a wider range of reefs and fish communities than those targeted by Halford et al. (2004) and Bellwood et al. (2006). We targeted small reef fishes (Pomacentridae) and most of the larger mobile fish 
species commonly observed across reefs of the GBR, including a range of coral-dependent and herbivorous taxa. We assessed temporal patterns of fish diversity, species abundances and community structure on 22 reefs that experienced coral declines. These reefs were spread over 10 degrees of latitude. By using such longterm and broad-scale data, we aimed to assess the variability in responses of different reef fish communities to declines in coral cover to gain a greater insight into fish and coral relationships and the likely impacts of predicted global coral declines on reef fishes of the GBR.

\section{MATERIALS AND METHODS}

Reef fish and benthic communities on 47 reefs of the GBR between 14 and $24^{\circ} \mathrm{S}$ were surveyed annually between 1995 and 2005. Reefs were situated in 3 positions on the continental shelf (inshore, mid-shelf and outer shelf). Three sites were established on the northeast flank of each reef; each consisting of 5 permanently marked $50 \mathrm{~m}$ transects that were randomly selected at depths between 6 and $9 \mathrm{~m}$. Detailed maps and further information on sampling methodology can be found in Sweatman et al. (2008, available online at www.aims.gov.au/docs/research/monitoring/reef/reefmonitoring.html). The abundances of 210 non-cryptic, diurnal fish species from 10 families (Acanthuridae, Chaetodontidae, Labridae, Lethrinidae, Lutjanidae, Pomacentridae, Scaridae, Serranidae, Siganidae and Zanclidae) were censused visually along each transect. Pomacentrids (all damselfish species) were counted in a $1 \mathrm{~m}$ wide belt, and all other families (large mobile fishes comprising over 140 target species), in a $5 \mathrm{~m}$ wide belt (Halford \& Thompson 1996). All fish species were classified as either coral-dependent (i.e. reliant on corals for food or shelter) or coral-independent, and as herbivores (i.e. predominantly feed on algae or detritus) or non-herbivores. Dietary preferences of fish species were mostly based on published information (Froese \& Pauly 2006, Wilson et al. 2008), while field observations provided information on a species' dependence on corals for shelter (i.e. fish retreated into coral colonies when threatened). Benthic community data were recorded along each transect using video (Abdo et al. 2003). Topographic complexity of reef habitat was not recorded in this study.

Fish species richness was the total number of species recorded at each site, and species abundances were summed to the level of site for all analyses. Hard coral cover at each site was expressed as the percentage of total substrate area based on analysis of 200 points per transect (Abdo et al. 2003). Percentage coral cover values were arcsine transformed prior to all analyses in order to improve normality and increase homogeneity of variances. Initially, we highlighted the time of minimum and maximum hard coral cover at every reef in the 11 yr survey period. For each reef where the time of maximum cover preceded that of the minimum (i.e. coral cover declined), we calculated the change in coral cover between those times, the associated change in $\log _{10}(x+1)$ fish species richness and the change in $\log _{10}(x+1)$ abundance of each fish species (only including species whose mean abundances were $>5$ in at least 1 survey). Data were log transformed to allow valid comparison of changes in abundance among reefs where base values were very different (i.e. a change from 10 to 1 may be as significant ecologically as a change from 100 to 10). We focussed on species-level abundances rather than total abundance to limit the effects of very abundant species. Linear regression was then used to assess the strength of association between changes in percentage coral cover and changes in both fish species richness and species abundances.

To examine some 'worst case' scenarios for reef fishes in more detail, we selected 7 reefs where coral cover had declined by at least $75 \%$ of the initial cover to an absolute value of $<10 \%$ (mean of $4.63 \pm 0.99 \mathrm{SE}$ ). Coral cover declines on 5 of these reefs (Low Isles, Thetford, Havannah Is., John Brewer and Rib) had been caused by a combination of crown-of-thorns starfish (COTS) outbreaks, coral bleaching and cyclones. Of the 2 remaining reefs, Fitzroy Is. suffered bleaching and COTS outbreaks, while coral declines at Gannet Cay were due only to COTS. Where multiple disturbances had occurred, it was not possible to assess the relative impact of each disturbance type on coral cover. At each worst case reef, coral cover remained very low for 4 to $6 \mathrm{yr}$ following the decline. To ensure the best chance of detecting changes in reef fish diversity at worst case reefs, we analysed 7 different diversity measures: species richness, Shannon's index, and 5 taxonomic indices that provide measures of taxonomic relatedness within a community based on the average taxonomic distance or path length between pairs of organisms traced through a taxonomic tree. Taxonomic indices included taxonomic diversity (Delta), taxonomic distinctness using both abundance data (Delta*) and presence/absence data (Delta+), total taxonomic distinctness (Sdelta+) and variation in taxonomic distinctness (Lambda+), all defined by Clarke \& Warwick $(1998,2001)$. Low values of taxonomic indices indicate habitat degradation (Warwick \& Clarke 1998). We used repeated-measures analysis of variance (RM ANOVA, SPSS Version 14.0) to assess whether there were significant changes in coral cover and fish diversity at each reef over time. When changes were significant $(p<0.05)$, we investi- 
gated whether these differences reflected any underlying linear or quadratic trends rather than sporadic fluctuations. When both coral cover and species richness of fishes declined significantly on a reef, we used Pearson's correlation ( $r$ ) to assess the strength and direction of a relationship.

In order to assess affects of coral declines on reef fish community structure at worst case reefs, we compared fish data from 3 successive years prior to the disturbance and 3 successive years after the disturbance (except at Havannah Is. where there was only 1 survey prior to coral decline). We used 3 yr pre- and post-disturbance for comparisons, as this was the maximum post-disturbance interval that was applicable to all worst case reefs. Where possible, we excluded counts made in the same year as disturbances to allow fish communities at least 1 yr to respond to reduced coral cover. To further ensure consistency among reefs, we only used post-disturbance data from 3 consecutive surveys made after coral cover fell to $<10 \%$. Non-metric multi-dimensional scaling (MDS) was used to investigate changes in fish community composition at the 7 worst case reefs and 3 'control' reefs using the Bray-Curtis similarity measure. The control reefs were the only study reefs that were located close to the worst case reefs, but did not experience major changes in coral cover during the study period. 'Control' reef data were from surveys coinciding with the 3 pre- and 3 post-disturbance surveys on the nearest worst case reefs. Differences between pre- and post-disturbance groups were estimated using analysis of similarities (ANOSIM). The contribution of each species to the average dissimilarity between pre- and post-disturbance groups was estimated using similarity percentage analyses (SIMPER). Analyses were performed separately for large mobile fish species and damselfishes, as damselfish abundances were often an order of magnitude greater than those of other taxa. Abundance data were square root transformed prior to analyses to down-weight the influence of very abundant species. All multivariate analyses were performed using PRIMER (Version 6.1.5, Plymouth Marine Laboratories).

We also calculated changes in mean abundance for each fish species between the 3 pre-disturbance and 3 post-disturbance surveys at each worst case and control reef. Only 1 yr of data was available from Havannah Is. prior to the disturbance, and only species whose mean abundances per site were $>5$ in at least 1 yr were included. To allow broad comparison of changes in species abundances among reefs without using multiple significance tests, we only considered a change to have occurred if mean abundances decreased or increased by $>25 \%$. This was based on Thompson \& Mapstone (1997), who found little power to detect changes in abundance of $<25 \%$ when using the same survey techniques on the same suite of GBR species.

\section{RESULTS}

\section{General patterns of species richness and abundance}

Of the 47 GBR reefs surveyed between 1995 and 2005, 22 suffered declines in coral cover of varying magnitude. The average period between maximum and minimum coral covers was $5.04 \mathrm{yr}( \pm 0.42 \mathrm{SE})$. Based on these 22 reefs, there was no significant linear relationship between declines in coral cover and changes in fish species richness (Fig. 1a). Both decreases and increases in abundance were common among species at all levels of coral decline, resulting in no significant linear relationship between changes in species abundances and declines in coral cover (Fig. 1b). We were also interested in whether changes in species abundances, irrespective of whether abundance increased or decreased, were greater when coral decreases were greater, so changes were converted to absolute values. Mean absolute changes in species abundances were positively associated with coral cover declines $\left(r^{2}=0.38, p<0.001\right.$; Fig. 1c). Species richness remained unaffected $\left(r^{2}=0.04, p=0.394\right)$ when analysed in the same fashion (Fig. 1c).

\section{Fish diversity at 'worst case' reefs}

Reef fish diversity was generally unaffected by declines in coral cover on the 7 worst case reefs (Fig. 2). Four widely used measures of diversity (species richness, Shannon's index, Delta* and Delta+) either did not change significantly over the study period or else varied through time, but did not track changes in coral cover (Table 1, Fig. 2). Analysis of 3 additional taxonomic diversity measures (Delta, Sdelta+ and Lambda+) produced similar results and did not provide any new insights (see supplementary Fig. A1 and Table A1 available at www.int-res.com/articles/suppl/ m372p211_app.pdf). Although coral cover declined at each reef $(p<0.001)$, indices of reef fish diversity only showed consistent temporal trends at 1 reef, Low Isles, but the direction of change was counterintuitive, with diversity tending to increase (Tables 1 \& A1, Figs. 2 \& A1). The only significant declining trends in diversity that were associated with significant effects of time occurred at Havannah Is. for Shannon's index (Table 1) and Lambda+ (Table A1), although these data were not significantly correlated with loss of coral cover $(r=0.29, p=0.45$ and $r=0.61, p=0.08$, respectively). 
a

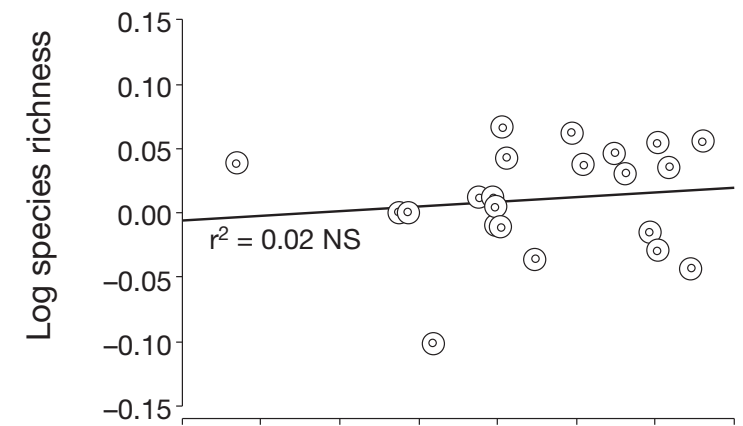

b

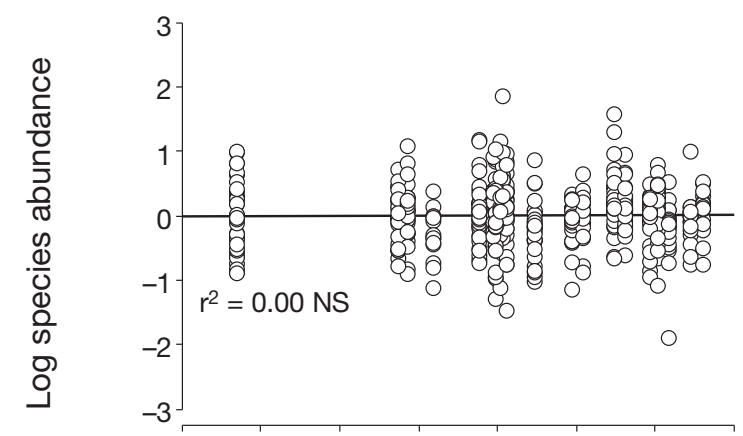

C

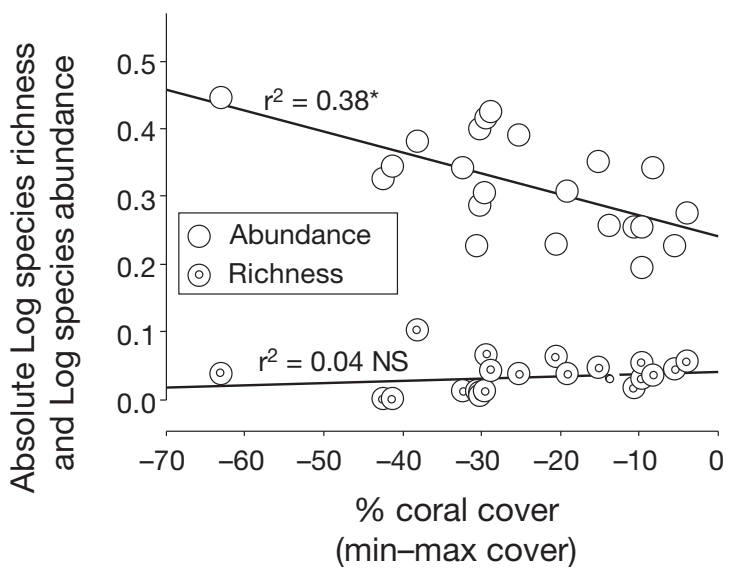

Fig. 1. Effects of coral cover declines on changes in: (a) mean fish species richness at each reef and (b) mean abundances of fish species. Each circle represents the value for an individual species and each column of circles represents 1 reef. (c) Each abundance data point represents the mean absolute change in abundance among all species at each reef. Species richness data in (c) is the same as that used in (a), but converted to absolute changes to allow comparison with abundance data. ${ }^{*} p<0.001$; NS: non-significant $(p>0.05)$

\section{Differences in community structure}

The structure of fish communities varied more in space than over time, with 3 inshore reefs (Havannah Is., Fitzroy Is. and Low Isles) clearly differing from the other reefs that are located on the mid- and outer reef shelf (Fig. 3). However, the structure of both large mobile fish and damselfish communities had changed significantly after major coral losses at the 7 worst case reefs (Global r-values $=0.749$ and 0.772 , respectively, with $\mathrm{p}<0.001$ in each case; Fig. 3). There were also smaller but still significant changes in communities of both large mobile fishes and damselfishes at the control reefs over the same period (Global r-values $=0.383$ and 0.506 with $\mathrm{p}=0.039$ and $\mathrm{p}<0.001$, respectively; Fig. 3). Stress values for both ordinations were low (Fig. 3), indicating that underlying dissimilarities were well represented.

Changes in abundance of 10 species explained nearly $27 \%$ of the dissimilarity in large mobile fish communities on worst case reefs from before and after disturbances (Table 2). However, the maximum contribution of any one species was only $3.84 \%$, suggesting that community changes involved a wide range of species. Three Chaetodon species, which depend on corals for food, were among these 10 species, contributing $8 \%$ of the community differences between them and declining in abundance in each case (Table 2). However, 6 of the top 10 species on worst case reefs were herbivores and were not coral dependent; together these contributed $16.51 \%$ to community differences (Table 2). Five of these herbivore species increased in abundance, while the abundance of Scarus psittacus declined on both worst case and control reefs (Table 2). Large herbivore and Chaetodon species (1 of which is dependent on corals for food) also contributed to changes on control reefs, and mean abundances mostly increased (Table 2). However, the magnitude of changes in abundance of the 3 species that contributed most to changes on control reefs were minimal compared with those on worst case reefs.

Changes in abundance of 10 species explained over $64 \%$ of the differences in damselfish communities on worst case reefs before and after disturbances and mostly reflected abundance decreases (Table 2). While decreases in abundance of a coral-dependent species (Pomacentrus moluccensis) contributed most (20.19\%), and this result was consistent among reefs (the dissimilarity/SD ratio was relatively high at 1.84), only 1 other coral-dependent species (Chromis atripectoralis) was among the 10 species that contributed most to dissimilarity (Table 2). Both species depend on coral for shelter. Decreases in abundance of Neopomacentrus azysron and Pomacentrus lepidogenys (neither obviously dependent on corals), contributed a combined $17.22 \%$ to community changes on worst case reefs, but abundances of these 2 species also decreased on control reefs, contributing $19.64 \%$. The algal-farming damselfish Pomacentrus wardi consistently increased in abundance on worst case reefs (the dissimilarity/SD ratio was relatively high at 1.56) and contributed $5.24 \%$ to community changes (Table 2). Damselfish community changes on control reefs were strongly influenced 


\section{Species richness (๑) Coral cover (०) \\ Shannon's index (ם) \\ Coral cover (๑)}
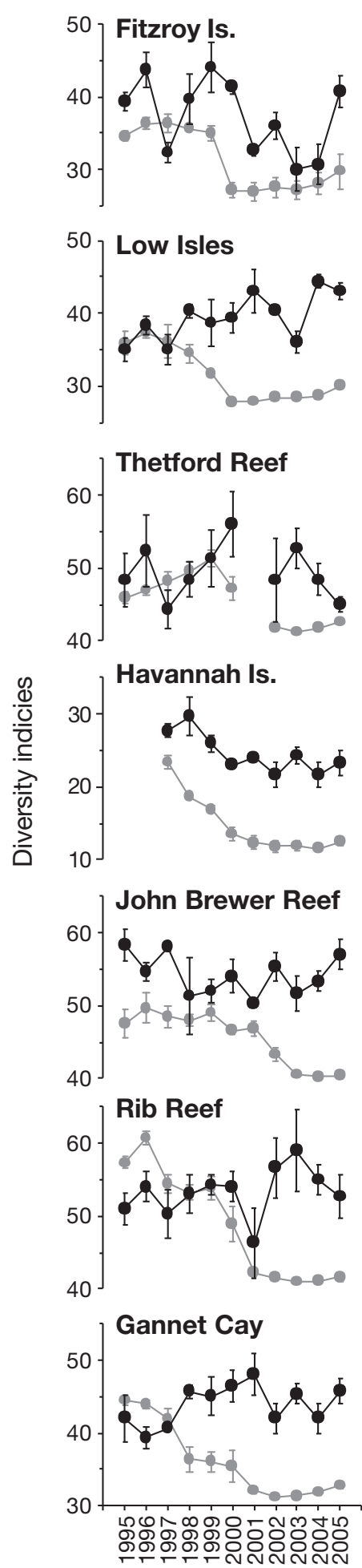
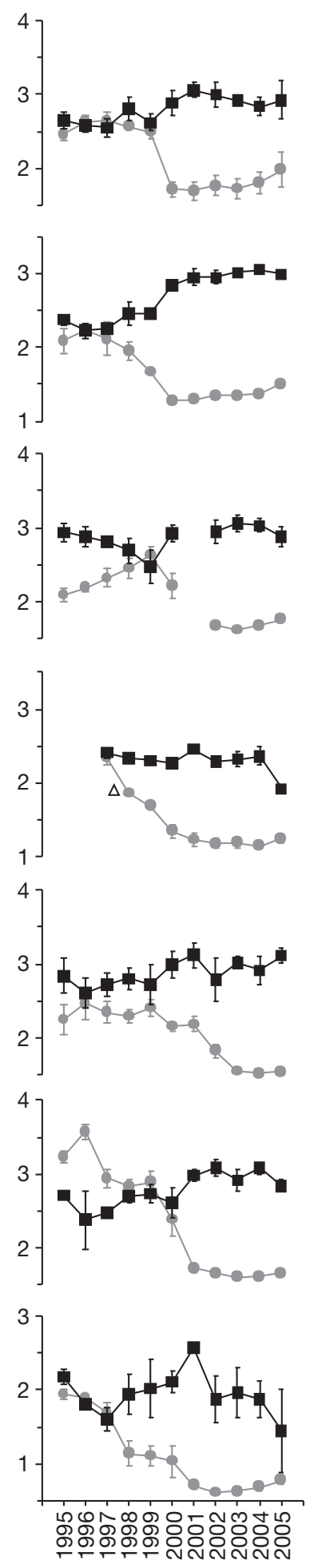

Year
Taxonomic distinctness: $\operatorname{Delta}^{*}(\boldsymbol{\Delta})$, Delta $+(\Delta)$

Coral cover (o)
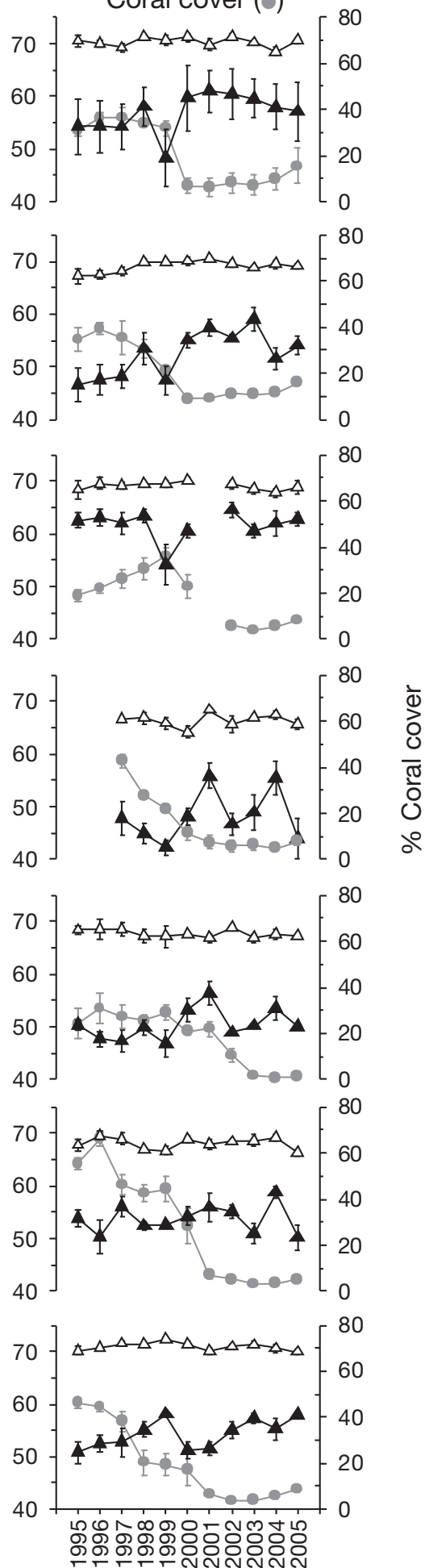

Fig. 2. Temporal changes in diversity indices (filled and open symbols, $y 1$-axis) for reef fishes at the 7 worst case reefs (means \pm $1 \mathrm{SE}$ ). Coral cover (filled grey circles, y2-axis) has been included in each plot for comparison. Havannah Is. was not surveyed in 1995 or 1996, and Thetford Reef was not surveyed in 2001 


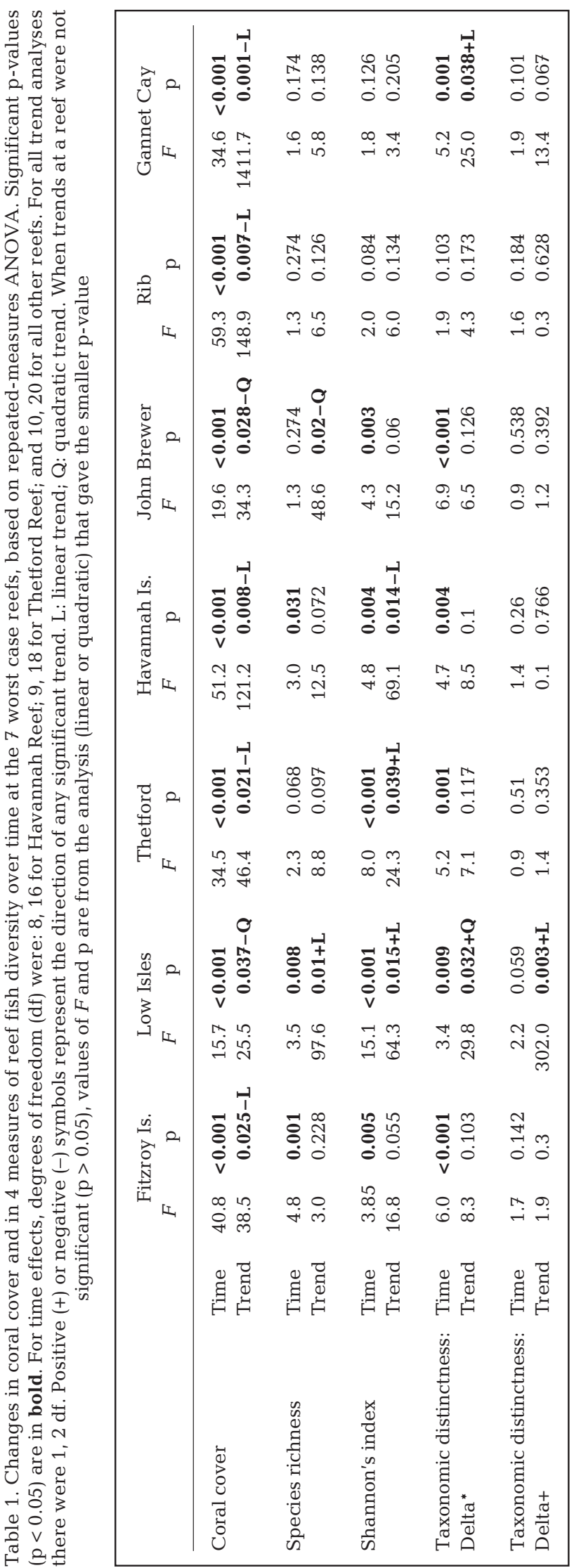

by increases in abundance of 5 planktivorous Chromis species (combined influence of $28.85 \%$; Table 2), with 2 being dependent on corals for shelter. In contrast, decreases in abundance of 2 Chromis species on worst case reefs contributed $10.46 \%$ to community changes (Table 2).

\section{Fish species abundances at worst case reefs}

The number of species that were sufficiently numerous to analyse for abundance changes ranged from 14 at Havannah Is. to 44 at John Brewer Reef. The nature of changes in species abundance varied considerably among the 7 worst case reefs (Fig. 4). Coral mortality appeared to cause widespread reduction in abundance at 3 reefs: $45 \%$ of species at Gannet Cay, $61 \%$ of species at Fitzroy Is. and $71 \%$ of species at Havannah Is. decreased in abundance by $>25 \%$ (Fig. 4), with 62 to $79 \%$ of those species having no obvious dependence on corals for food or shelter. In addition, few species increased substantially in abundance at those 3 worst case reefs (Fig. 4). In contrast, fewer species decreased in abundance at nearby control reefs (17\% at East Cay, $13 \%$ at Michaelmas Reef and $29 \%$ at Dip Reef), and large increases were more common. More species showed very large decreases and increases in abundance at John Brewer Reef and Rib Reef than at the nearest undisturbed reef (Dip Reef). More species decreased in abundance at Thetford Reef (25\%) compared with the nearby control reef (Michaelmas Reef), but the numbers of species whose abundances increased were similar. The number of species that increased and decreased in abundance were similar at Low Isles and the undisturbed Michaelmas Reef (Fig. 4).

Given the contribution of large herbivore species to community dissimilarity and their perceived importance to reef resilience, we also assessed variability in their changes in abundance among the reefs. The numbers of herbivore species that increased in abundance following coral declines were consistently high on 4 worst case reefs at the latitudes 16 to $17^{\circ} \mathrm{S}$ (Low Isles, Thetford) and 18 to $19^{\circ} \mathrm{S}$ (John Brewer and Rib) (Fig. 5); $68.4 \%$ ( $\pm 6.5 \mathrm{SE}$ ) of common herbivore species increased in abundance and $12.3 \%( \pm 2.3)$ decreased in abundance on these 4 reefs, compared with $21.6 \%$ $( \pm 3.4)$ that increased and $17.8 \%( \pm 9.5)$ that decreased on 2 nearby control reefs. The number of herbivore species that increased in abundance at Gannet Cay (21 to $22^{\circ} \mathrm{S}$ ) exceeded the number that decreased, although relatively more species increased in abundance on the nearby control reef (Fig. 5). Large herbivores were uncommon on the 2 remaining worst case reefs, Havannah Is. and Fitzroy Is.; only 2 species were sufficiently abundant to analyse on each reef (Fig. 5). 


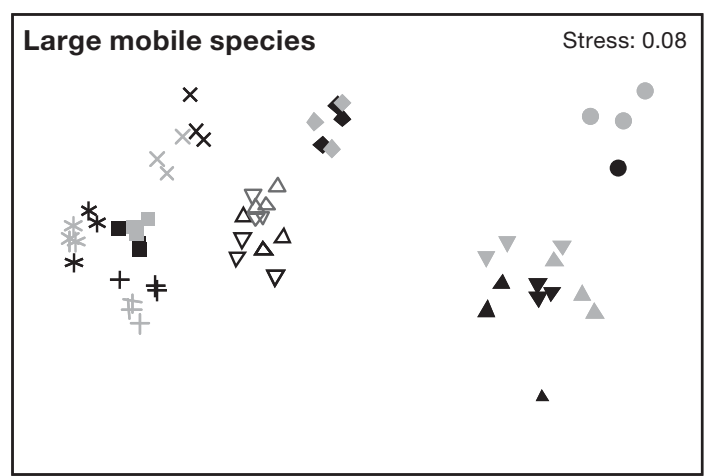

Control: Global $r=0.383, p=0.039$

Worst case: Global $r=0.749, p<0.001$

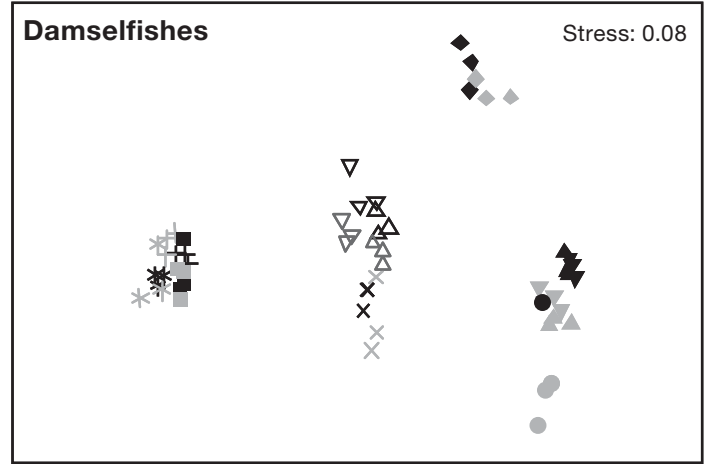

Control: Global $r=0.506, p<0.001$

Worst case: Global $r=0.772, p<0.001$

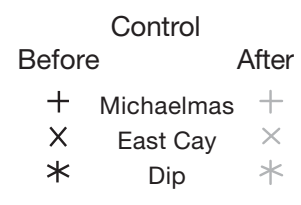

\begin{tabular}{|c|c|c|}
\hline \multicolumn{3}{|c|}{ Worst case } \\
\hline Before & & After \\
\hline $\boldsymbol{\Delta}$ & Fitzroy Is. & $\Delta$ \\
\hline 7 & Low Isles & V \\
\hline $\mathbf{\square}$ & Thetford & - \\
\hline$\gamma$ & Gannett Cay & 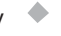 \\
\hline • & Havannah Is. & ○ \\
\hline$\Delta$ & John Brewer & $\triangle$ \\
\hline$\nabla$ & Rib & $\nabla$ \\
\hline
\end{tabular}

Fig. 3. MDS ordinations using square-root-transformed fish species abundance data from 3 surveys before disturbances and 3 surveys after disturbances at the 7 worst case reefs and 3 control reefs. ANOSIM results are displayed below each panel

conspecifics (Sweatman 1985). At another level, taxonomic diversity reflects ecological diversity, so maintenance of a wide taxonomic range of species should also confer greater stability on a community during major perturbations through functional redundancy (Rogers et al. 1999). However, this will only be true if representatives of crucial functional groups are present in sufficient numbers to perform their roles adequately. Decreases in abundances of individual species can have negative consequences for ecosystems despite stable patterns of diversity (Chapin et al. 2000, Bellwood et al. 2004, Folke et al. 2004). We found that fish diversity was generally maintained following coral declines, while abundances of up to $71 \%$ of the fish species decreased. Such widespread abundance decreases might lead to loss of ecosystem function, suggesting that stable patterns of reef fish diversity provided false assurance of ecosystem resilience. Currently, the significance of the functional roles of many fish taxa to coral reef resilience is not known, nor is it clear what

\section{DISCUSSION}

Maintenance of high ecosystem diversity is a key conservation goal because of the apparent positive relationship between diversity and ecosystem properties (Hooper et al. 2005, Worm et al. 2006). In marine ecosystems, resilience and resistance to disturbances appear likely to be enhanced by high species richness (Loreau et al. 2002), particularly among crucial functional groups (Hughes et al. 2007). While high diversity is undoubtedly desirable, our results showed that major coral declines led to changes in associated reef fish communities that could be detrimental to reef ecosystems, even though fish diversity was maintained.

Our finding that reef fish diversity was maintained despite large coral declines is compelling, because both the conventional measures of species richness and Shannon's Index, as well as taxonomy-based measures, all produced broadly similar patterns. This is encouraging at one level, since maintenance of fish diversity should assist recovery of fish species whose abundances declined with coral cover; repopulation of fish on recovering reefs may be highly dependent on self-recruitment (return of larvae to their natal reef; Jones et al. 1999, Almany et al. 2007) and recruitment of some fish species is facilitated by the presence of abundances of fishes are necessary to retain ecosystem services. Even single or relatively rare species may affect ecosystem resilience and pathways of energy and material flow (Bellwood et al. 2003, 2006, Hooper et al. 2005). Further research into the ecological roles performed by reef fishes may provide clearer insights into the relationship between fish communities and reef resilience.

The lack of change in fish diversity observed in the present study contrasts starkly with the major losses of fish diversity recorded in Papua New Guinea (Jones et al. 2004), Tanzania (Garpe et al. 2006) (both based on species richness) and the Seychelles (Graham et al. 2006) (based on species richness and Delta+) after similar coral declines. However, the only 2 comparable long-term studies on the GBR produced differing results. One study found decreases in species richness with loss of coral on the slopes of 4 southern reefs (Halford et al. 2004). The other study of fish diversity on small bommies at a single reef (Bellwood et al. 2006) used species richness and Shannon's Index and found, as in the present study, that diversity of fish communities changed little with major loss of coral, though there were distinct shifts in community structure. It is unclear why large declines in coral cover cause less change in fish diversity on GBR reefs than on reefs in 
Table 2. Fish species that made the greatest contribution to the average community dissimilarity between pre- and post-disturbance periods on worst case and control reefs, based on SIMPER analyses. Large mobile fishes and damselfishes were analysed separately, and 10 species that most influenced community dissimilarity were included in each case. Dissimilarity/SD (standard deviation) represents the consistency with which a species contributes to overall dissimilarity; the higher the value, the higher the discriminating power of that species. H: herbivores (note that Ctenochaetus spp. are strictly detritus feeders); C: coral-dependent species

\begin{tabular}{|c|c|c|c|c|c|c|c|}
\hline Species & $\begin{array}{l}\text { Feeding } \\
\text { type }\end{array}$ & $\begin{array}{c}\text { Mean ab } \\
\text { Before }\end{array}$ & $\begin{array}{l}\text { Indance } \\
\text { After }\end{array}$ & $\begin{array}{c}\text { Average } \\
\text { dissimilarity }\end{array}$ & $\begin{array}{c}\text { Dissimilarity/ } \\
\text { SD }\end{array}$ & $\begin{array}{c}\text { Contribution } \\
(\%)\end{array}$ & $\begin{array}{c}\text { Cumulative } \\
(\%)\end{array}$ \\
\hline \multicolumn{8}{|l|}{ Large mobile species } \\
\hline \multicolumn{8}{|l|}{ Worst case reefs } \\
\hline Scarus rivulatus & $\mathrm{H}$ & 1.88 & 3.16 & 1.17 & 1.23 & 3.84 & 3.84 \\
\hline Chaetodon aureofasciatus & $\mathrm{C}$ & 2.41 & 1.25 & 1.06 & 1.29 & 3.48 & 7.32 \\
\hline Scarus psittacus & $\mathrm{H}$ & 2.19 & 1.28 & 0.9 & 1 & 2.95 & 10.28 \\
\hline Siganus doliatus & $\mathrm{H}$ & 2.02 & 2.06 & 0.88 & 0.96 & 2.9 & 13.18 \\
\hline Acanthurus blochi & $\mathrm{H}$ & 0.32 & 1.29 & 0.84 & 1.46 & 2.78 & 15.96 \\
\hline Chaetodon rainfordi & $\mathrm{C}$ & 2.08 & 1.06 & 0.79 & 1.54 & 2.61 & 18.56 \\
\hline Lutjanus vitta & & 0.87 & 1.06 & 0.65 & 0.63 & 2.13 & 20.7 \\
\hline Naso unicornis & $\mathrm{H}$ & 0.75 & 1.31 & 0.64 & 1.1 & 2.1 & 22.79 \\
\hline Chlorurus sordidus & $\mathrm{H}$ & 2.9 & 3.09 & 0.59 & 1.3 & 1.94 & 24.74 \\
\hline Chaetodon trifasciatus & $\mathrm{C}$ & 1.68 & 1.29 & 0.58 & 1.13 & 1.91 & 26.64 \\
\hline \multicolumn{8}{|l|}{ Control reefs } \\
\hline Scarus psittacus & $\mathrm{H}$ & 2.12 & 1.8 & 0.79 & 1.68 & 3.03 & 3.03 \\
\hline Acanthurus nigrofuscus & $\mathrm{H}$ & 4.4 & 4.51 & 0.75 & 1.46 & 2.86 & 5.89 \\
\hline Ctenochaetus spp. & $\mathrm{H}$ & 5.87 & 6.05 & 0.74 & 1.03 & 2.85 & 8.74 \\
\hline Chlorurus sordidus & $\mathrm{H}$ & 3.04 & 3.7 & 0.65 & 1.34 & 2.49 & 11.23 \\
\hline Chaetodon trifascialis & $\mathrm{C}$ & 0.69 & 1.56 & 0.6 & 1.83 & 2.32 & 13.54 \\
\hline Lutjanus gibbus & & 0.38 & 0.78 & 0.55 & 0.55 & 2.12 & 15.66 \\
\hline Scarus globiceps & $\mathrm{H}$ & 1.58 & 1.55 & 0.55 & 1.38 & 2.1 & 17.76 \\
\hline Hipposcarus longiceps & $\mathrm{H}$ & 0.75 & 1.01 & 0.52 & 0.69 & 1.99 & 19.74 \\
\hline Chaetodon citrinellus & & 1.45 & 2.09 & 0.52 & 1.33 & 1.98 & 21.73 \\
\hline Lutjanus fulviflamma & & 1.11 & 0.39 & 0.51 & 0.74 & 1.94 & 23.67 \\
\hline \multicolumn{8}{|l|}{ Damselfishes } \\
\hline \multicolumn{8}{|l|}{ Worst case reefs } \\
\hline Pomacentrus moluccensis & $\mathrm{C}$ & 12.29 & 5.81 & 4.78 & 1.84 & 20.19 & 20.19 \\
\hline Neopomacentrus azysron & & 6.73 & 5.09 & 2.57 & 1.08 & 10.83 & 31.02 \\
\hline Chromis atripectoralis & $\mathrm{C}$ & 4.81 & 1.8 & 1.88 & 0.97 & 7.95 & 38.97 \\
\hline Pomacentrus lepidogenys & & 8.06 & 6.92 & 1.51 & 1.28 & 6.39 & 45.35 \\
\hline Pomacentrus wardi & $\mathrm{H}$ & 4.52 & 5.4 & 1.24 & 1.56 & 5.24 & 50.6 \\
\hline Acanthochromis polyacanthus & & 2.75 & 3.81 & 0.76 & 1.33 & 3.22 & 53.82 \\
\hline Pomacentrus adelus & & 2.3 & 1.72 & 0.71 & 0.83 & 2.99 & 56.81 \\
\hline Chrysiptera rollandi & & 2.57 & 2.08 & 0.63 & 1.02 & 2.65 & 59.46 \\
\hline Chromis nitida & & 4.05 & 3.67 & 0.6 & 0.37 & 2.51 & 61.97 \\
\hline Neopomacentrus bankieri & & 1.26 & 1.66 & 0.57 & 0.56 & 2.42 & 64.39 \\
\hline \multicolumn{8}{|l|}{ Control reefs } \\
\hline Neopomacentrus azysron & & 8.11 & 6.22 & 2.08 & 1.33 & 10.75 & 10.75 \\
\hline Pomacentrus lepidogenys & & 11.66 & 10.61 & 1.72 & 1.47 & 8.89 & 19.64 \\
\hline Chromis atripectoralis & $\mathrm{C}$ & 1.42 & 3.16 & 1.55 & 1.18 & 8 & 27.64 \\
\hline Chromis weberi & & 0.39 & 2.67 & 1.52 & 0.83 & 7.86 & 35.49 \\
\hline Chromis ternatensis & $\mathrm{C}$ & 1.56 & 2.91 & 1.04 & 0.82 & 5.36 & 40.86 \\
\hline Chromis lepidolepis & & 2.01 & 2.43 & 0.84 & 1.14 & 4.33 & 45.19 \\
\hline Pomacentrus coelestis & & 1.28 & 1.48 & 0.72 & 1.25 & 3.72 & 48.91 \\
\hline Chromis margaritifer & & 3.78 & 4.07 & 0.64 & 0.98 & 3.3 & 52.21 \\
\hline Pomacentrus philippinus & & 4.66 & 4.38 & 0.6 & 1.47 & 3.12 & 55.33 \\
\hline Amblyglyphidodon curacao & $\mathrm{C}$ & 2.11 & 1.82 & 0.52 & 1.23 & 2.69 & 58.02 \\
\hline
\end{tabular}

other parts of the world. Factors that may hamper maintenance of fish diversity following disturbances to corals include reduction in habitat complexity (Syms \& Jones 2000), reef isolation and therefore uncertain replenishment from undisturbed reefs (Cowen et al. 2006) and ongoing human-induced stressors.
Loss of habitat complexity appeared to be a major cause of declines in reef fish diversity following coral mortality in 3 comparable long-term studies (Halford et al. 2004, Garpe et al. 2006, Graham et al. 2006). Once coral structures erode or are broken into rubble, overall reef structural complexity is reduced and fish 


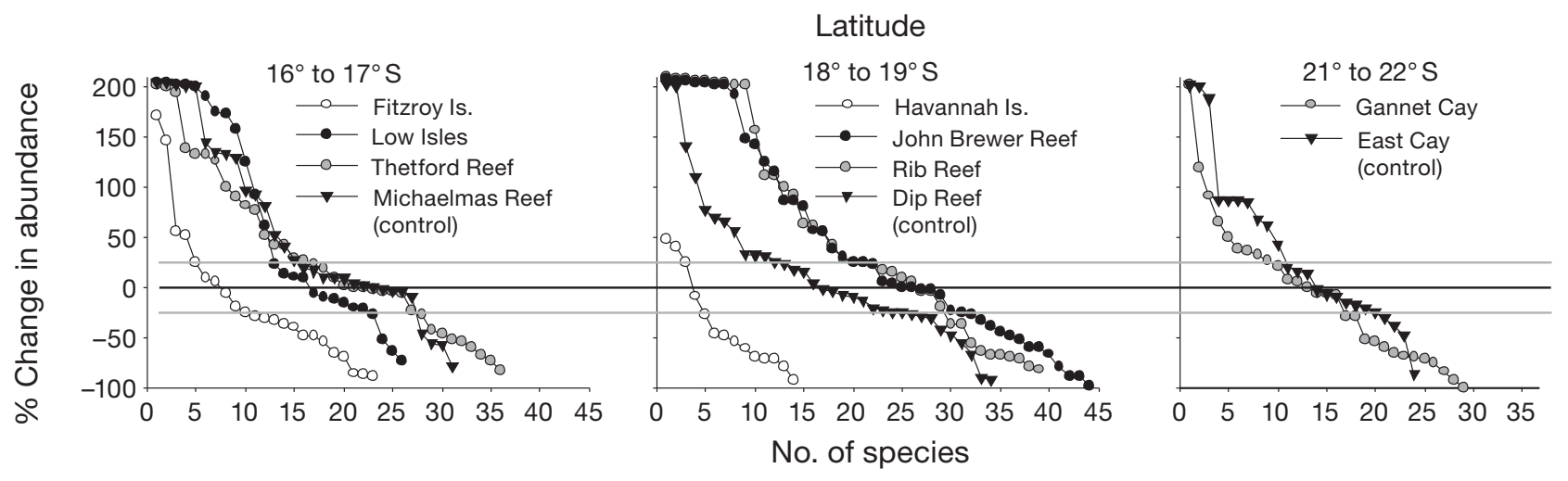

Fig. 4. Percent changes in abundances of fish species (large mobile species and damselfishes) following declines in coral cover at the 7 worst case reefs and 3 control reefs, grouped by latitude (to indicate the appropriate control reef for each group of worst case reefs). Percent change for each species was calculated from the average abundance of 3 surveys when coral cover was maximal (a single survey in the case of Havannah Is.) and the 3 surveys when coral cover was minimal. Species percent changes are ranked from largest increases to largest decreases along the $x$-axis. The area bounded by the light grey lines represents increases or decreases of $<25 \%$ that may be due to sampling error (Thompson \& Mapstone 1997). To save space, percent changes $>200 \%$ are displayed in $1 \%$ incremenents

diversity may decrease (Graham et al. 2006). Fish communities may be particularly at risk from loss of coral structures where the topographic complexity of the underlying substrate is very low so that most of the structural relief is provided by the corals themselves, as occurred on the southern GBR (Halford et al. 2004, Emslie et al. 2008). We did not estimate topographic complexity in our surveys, but visual observations suggested that many dead coral skeletons were either still in life position at worst case reefs or that underlying

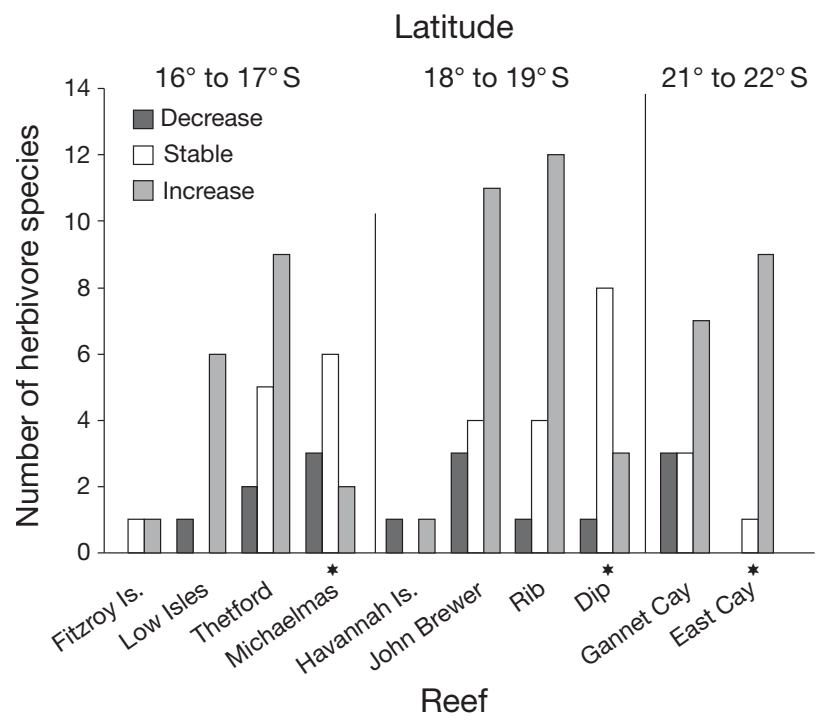

Fig. 5. Number of large herbivore species showing different abundance trajectories following coral declines on worst case and control $\left({ }^{*}\right)$ reefs grouped by latitude (to indicate the appropriate control reef for each group of worst case reefs). 'Stable' abundances represent changes $<25 \%$ that may be due to sampling error (Thompson \& Mapstone 1997). Increases or decreases in abundance represent changes $>25 \%$ substrate complexity was high. Thus, sufficient habitat complexity may have remained after the losses of living coral, allowing many species to persist (albeit in lower numbers in some cases). Havannah Is. was the exception; here, bleached coral skeletons were reduced to rubble by storm action and the relatively flat rubble banks were then overgrown by macroalgae (Sweatman et al. 2008). Two indices of fish diversity declined at Havannah Is., and the greatest proportion of species decreased in abundance.

Other long-term studies have mainly focused on relatively small or isolated reef systems that were all subject to severe disturbances so that the capacity for recovery from local fish stocks was reduced and reliance on external sources of larvae for maintenance of diversity was increased (see Graham et al. 2006). The GBR represents a large, dense mosaic of reefs, and connectivity is likely to be very high among the closely spaced reefs (James et al. 2002), so losses from one reef can potentially be replenished by larvae from many other reefs. The major disturbances in our study were localised, so adjacent reefs retained high coral cover and were potential sources of coral and fish recruits for the study reefs. The sites of other studies were also exposed to various combinations of potential stressors that may affect biodiversity, such as high fishing pressure, terrestrial runoff, macroalgal overgrowth and limited management resources. In contrast, reefs of the GBR are relatively free of these stressors; there is little obvious coastal pollution, fishing pressure is modest on a global scale and wide-ranging management practises are in place to limit anthropogenic stresses (Lawrence et al. 2002).

Not surprisingly, decreases in abundance of coraldependent taxa (certain Chaetodon, Pomacentrus and 
Chromis species in particular) contributed to community changes on worst case reefs (Syms \& Jones 2000, Pratchett et al. 2006, Wilson et al. 2006). However, up to $79 \%$ of species that declined in abundance on these reefs were not obviously dependent on corals, suggesting that loss of corals affected a wider range of fish species than was expected from known patterns of juvenile and adult habitat use. This may reflect loss of important habitat for cryptic post-larval fishes; reef fish species often undergo ontogenetic shifts in habitat use, and many species that are not obviously associated with corals in later life rely on corals for successful settlement at the end of their larval phase (Jones et al. 2004, Feary et al. 2007). Decreases in abundance of species that are less reliant on coral cover have also been linked to loss of shelter due to eventual collapse of coral skeletons (Garpe et al. 2006, Graham et al. 2006). Damselfish species in particular declined in abundance on highly disturbed reefs compared with control reefs, suggesting that there had been some general and detrimental impact of coral mortality on this family. All damselfishes are small-bodied and tend to be very site-attached, so any disturbances that affect habitat complexity and composition on a small scale are likely to have a greater impact on these species than on larger, more mobile fishes. Consistent decreases in abundance of Pomacentrus moluccensis following coral declines contributed most to damselfish community dissimilarities. This species has responded similarly in other, smaller-scale studies on the GBR (Booth \& Beretta 2002, Cheal et al. 2002, Bellwood et al. 2006). P. moluccensis is very susceptible to disturbance as its preferred habitat, small branching corals (Wilson et al. 2008), are vulnerable to a wide range of disturbances, such as bleaching, tropical storms and outbreaks of COTS. Strong associations between abundances of piscivorous fish and their prey have been recorded on the GBR (Stewart \& Jones 2001). Given that small damselfishes, including $P$. moluccensis, are common prey for predatory fishes on the GBR (Graham et al. 2003), declines in damselfish abundance following coral mortality may affect higher trophic levels.

In previous studies, responses of herbivorous fishes to coral declines have been variable; algal cover always increases following coral mortality, but observations of concomitant increases in herbivore abundance have been inconsistent (Wilson et al. 2006). Our results showed that increases in abundance of large herbivores contributed considerably to community changes following coral declines and that a high proportion of herbivore species had increased in abundance on 4 worst case reefs, presumably due to migration into areas of greater food availability (Wilson et. al. 2006) or enhanced recruitment success following algal increases (Birkeland \& Lucas 1990). These results are encouraging, as the grazing activities of herbivorous fishes are thought to reduce the probability of phase shifts to algal dominance and to enhance coral recruitment (Bellwood et al. 2004, Mumby et al. 2006, Hughes et al. 2007). However, herbivorous fishes are not all equally effective in enhancing reef resilience (Bellwood et al. 2006, Ledlie et al. 2007, Mantyka \& Bellwood 2007). Ultimately, the capacity of these animals to prevent further reef degradation following coral declines may depend not just on the presence of key species, but on their presence in sufficient numbers to fulfil their ecosystem function. Increases in abundance of large herbivores following disturbances may also be temporary if coral recovery is minimal and erosion of coral skeletons causes subsequent reductions in structural complexity (see Garpe et al. 2006, Graham et al. 2006). Unlike in many other regions, herbivorous reef fishes on the GBR are currently not exploited, though this may change if stocks of preferred fishes decline.

Although changes in abundance of certain taxa contributed consistently to major shifts in reef fish community structure, there was still great variability in responses among fish communities. For example, 3 inshore reefs (Havannah Is., Low Isles and Fitzroy Is.) started with broadly similar fish communities and suffered similar coral declines, yet responses of fish communities varied: over 3 times as many species decreased in abundance at Fitzroy Is. and Havannah Is. compared with Low Isles, and diversity at Low Isles increased. The comparison between Low Isles and Havannah Is. is particularly interesting because both experienced a similar sequence of disturbances, whereby COTS outbreaks or bleaching first killed living corals, but left the skeletons intact, then coral skeletons were broken and redistributed by storms. Variation in the magnitude and trajectory of responses of fish communities at these 2 reefs to such similar sequences of disturbances suggests that factors other than coral cover (i.e. topographic complexity, larval connectivity and anthropogenic stressors, as discussed earlier) play key roles in determining the nature of reef fish communities and that some reef communities on the GBR may be naturally less resilient than others. Inshore reefs such as Havannah Is. and Fitzroy Is. that support relatively few herbivores may be particularly at risk of further degradation following coral declines as the rate of algal growth may well exceed the capacity of fish populations to keep it in check (Williams et al. 2001, Mumby et al. 2006).

Compared with other coral reef regions of the world, the GBR has remained relatively unmodified (Pandolfi et al. 2003). Reefs in many regions are not so fortunate, being exposed to multiple stressors (e.g. pollution, sedimentation and overfishing) that destabilize fish 
and coral populations and lead to long-term reef degradation (Bellwood et al. 2004). Some coral and fish communities in the southern GBR have shown resilience following extensive coral losses by returning to pre-disturbance structures within a decade (Halford et al. 2004), and our worst case reefs may recover similarly. However, in the longer term, our data suggest that predicted increases in the frequency, severity and scale of coral mortality due to global warming (HoeghGuldberg 2004) will cause simultaneous changes in reef fish communities on the GBR over unprecedented spatial scales. This could reduce the rate of recovery, as the current resilience of the GBR is probably linked to the small-scale patchiness of coral mortality and replenishment by larvae from nearby, undisturbed reefs. Furthermore, coral mortality represents only one of many potential impacts of global warming on reef fishes; other climate-mediated factors will affect the responses of fishes to coral declines. For example, changes in broad-scale climate may alter physical conditions (i.e. water temperature and major ocean currents) that drive marine food webs and strongly influence reef fish population growth over large areas of the GBR (Cheal et al. 2007), while elevated ocean temperatures could dramatically reduce survival of young reef fishes (Gagliano et al. 2007). To better understand and manage the effects of future climate change on coral reefs, it is necessary to increase our knowledge of the links between reef organisms and ecosystem resilience, and to minimise anthropogenic stresses that so commonly contribute to coral reef degradation around the world.

Acknowledgements. Some of the data used in this study were collected by members of the AIMS long-term monitoring team who were not directly involved with this paper. To those people we extend our thanks. S.K.W. was supported by the Leverhulme Trust.

\section{LITERATURE CITED}

Abdo D, Burgess S, Coleman G, Osborne K (2003) Long term monitoring of the Great Barrier Reef, Standard Operating Procedure No. 9. Australian Institute of Marine Science, Townsville

Almany GR, Berumen ML, Thorrold SR, Planes S, Jones GP (2007) Local replenishment of coral reef fish populations in a marine reserve. Science 316:742-744

Bellwood DR, Hoey AS, Choat JH (2003) Limited functional redundancy in high diversity ecosystems; resilience and ecosystem function on coral reefs. Ecol Lett 6:281-285

Bellwood DR, Hughes TP, Folke C, Nystrom M (2004) Confronting the coral reef crisis. Nature 429:827-833

Bellwood DR, Hoey AS, Ackerman JL, Depczynski M (2006) Coral bleaching, reef fish community phase shifts and the resilience of coral reefs. Glob Change Biol 12:1587-1594

Birkeland C, Lucas JS (1990) Acanthaster planci: major management problems of coral reefs. CRC Press, Boca Raton, FL
Booth DJ, Beretta GA (2002) Changes in a fish assemblage after a coral bleaching event. Mar Ecol Prog Ser 245: 205-212

Bouchon-Navaro Y, Bouchon C, Harmelin-Vivien ML (1985) Impact of coral degradation on a chaetodontid fish assemblage (Moorea, French Polynesia). In: Gabrié C et al. (eds) Proc 5th Int Coral Reef Congr, Vol 5. Antenne MuseumEPHE, Moorea, Tahiti, p 427-432

Chapin FS, Zavaleta ES, Eviner VT, Naylor RL and others (2000) Consequences of changing biodiversity. Nature 405:234-242

Cheal AJ, Coleman G, Delean S, Miller I, Osborne K, Sweatman H (2002) Responses of coral and fish assemblages to a severe but short-lived tropical cyclone on the Great Barrier Reef, Australia. Coral Reefs 21:131-142

Cheal AJ, Delean S, Sweatman H, Thompson AA (2007) Spatial synchrony in coral reef fish populations and the influence of climate. Ecology 88:158-169

Clarke KR, Warwick RM (1998) A taxonomic distinctness index and its statistical properties. J Appl Ecol 35:523-531

Clarke KR, Warwick RM (2001) A further biodiversity index applicable to species lists: variation in taxonomic distinctness. Mar Ecol Prog Ser 216:265-278

Cowen RK, Paris CB, Srinivasan A (2006) Scaling of connectivity in marine populations. Science 311:522-527

Emslie MJ, Cheal AJ, Sweatman H, Delean S (2008) Recovery from disturbance of coral and reef fish communities on the Great Barrier Reef, Australia. Mar Ecol Prog Ser 371: $177-190$

Feary DA, Almany GR, Jones GP, McCormick MI (2007) Coral degradation and the structure of tropical reef fish communities. Mar Ecol Prog Ser 333:243-248

Folke C, Carpenter S, Walker B, Scheffer M, Elmqvist T, Gunderson L, Holling CS (2004) Regime shifts, resilience and biodiversity in ecosystem management. Annu Rev Ecol Evol Syst 35:557-581

Froese R, Pauly D (2006) FishBase. Available at www.fishbase. org. Accessed in March 2008

> Gagliano M, McCormick MI, Meekan MG (2007) Temperature-induced shifts in selective pressure at a critical developmental transition. Oecologia 152:219-225

Garpe KC, Yahya SAS, Lindahl U, Ohman MC (2006) Longterm effects of the 1998 coral bleaching event on reef fish assemblages. Mar Ecol Prog Ser 315:237-247

> Graham NAJ, Evans RD, Russ GR (2003) The effects of marine reserve protection on the trophic relationships of reef fishes on the Great Barrier Reef. Environ Conserv 30: 200-208

Graham NAJ, Wilson SK, Jennings S, Polunin NVC, Bijoux JP, Robinson J (2006) Dynamic fragility of oceanic coral reef systems. Proc Natl Acad Sci USA 103:8425-8429

Halford AR, Thompson AA (1996) Standard Operating Procedure No. 3. Australian Institute of Marine Science, Townsville

> Halford AR, Cheal AJ, Ryan D, Williams DMcB (2004) Resilience to large-scale disturbance in coral and fish assemblages on the Great Barrier Reef, Australia. Ecology 85: 1892-1905

Hoegh-Guldberg O (2004) Coral reefs in a century of rapid change. Symbiosis 37:1-31

> Hooper DU, Chapin FS, Ewel JJ, Hector A and others (2005) Effects of biodiversity on ecosystem functioning: a consensus of current knowledge. Ecol Monogr 75:3-35

> Hughes TP, Rodrigues MJ, Bellwood DR, Ceccarelli D and others (2007) Phase shifts, herbivory and the resilience of coral reefs to climate change. Curr Biol 17:360-365

James MK, Armsworth PR, Mason LB, Bode L (2002) The 
structure of reef fish metapopulations: modeling larval dispersal and retention patterns. Proc R Soc Lond B Biol Sci 269:2079-2086

> Jones GP, Syms C (1998) Disturbance, habitat structure and the ecology of fishes on coral reefs. Aust J Ecol 23:287-297

Jones GP, Milicich MJ, Emslie MJ, Lunow C (1999) Selfrecruitment in a coral reef fish population. Nature 402: 802-804

Jones GP, McCormick MI, Srinivasan M, Eagle JV (2004) Coral decline threatens fish biodiversity in marine reserves. Proc Natl Acad Sci USA 101:8251-8253

Lawrence D, Kenchington R, Woodley S (2002) The Great Barrier Reef: finding the right balance. Melbourne University Press, Melbourne

Ledlie MH, Graham NAJ, Bythell JC, Wilson SK, Jennings S, Polunin NVC, Hardcastle J (2007) Phase shifts and the role of herbivory in the resilience of coral reefs. Coral Reefs 26: 641-653

Loreau M, Shahid N, Inchausti P (2002) Biodiversity and ecosystem functioning: synthesis and perspectives. Oxford University Press, Oxford

Mantyka CS, Bellwood DR (2007) Direct evaluation of macroalgal removal by herbivorous coral reef fishes. Coral Reefs 26:435-442

Moberg F, Folke C (1999) Ecological goods and services of coral reef ecosystems. Ecol Econ 29:215-233

Mumby PJ, Dahlgren CP, Harborne AR, Kappel CV and others (2006) Fishing, trophic cascades and the process of grazing on coral reefs. Science 311:98-101

Munday PL, Jones GP, Sheaves M, Williams AJ, Goby G (2007) Vulnerability of fishes of the Great Barrier Reef to climate change. Great Barrier Reef Marine Park Authority and Greenhouse Office, Townsville, p 357-391

Pandolfi JM, Bradbury RH, Sala E, Hughes TP and others (2003) Global trajectories of the long-term decline of coral reef ecosystems. Science 301:955-958

Pratchett MS, Wilson SK, Baird AH (2006) Declines in the abundance of Chaetodon butterfly fishes following extensive coral depletions. J Fish Biol 69:1269-1280

Pratchett MS, Munday PL, Wilson SK, Graham NAJ and others (2008) Effects of climate-induced coral bleaching on coral reef fishes - ecological and economic consequences. Oceanogr Mar Biol Annu Rev 46:251-296

Risk MJ (1972) Fish diversity on a coral reef in the Virgin Islands. Atoll Res Bull 193:1-6

Rogers SI, Clarke KR, Reynolds JD (1999) The taxonomic distinctness of coastal bottom dwelling fish communities of the north-east Atlantic. J Anim Ecol 68:769-782

Sano M (2000) Stability of reef fish assemblages: responses to coral recovery after catastrophic predation by Acanthaster planci. Mar Ecol Prog Ser 198:121-130

Editorial responsibility: Charles Birkeland, Honolulu, Hawaii, USA
Sano M, Shimizu M, Nose Y (1987) Long-term effects of destruction of hermatypic corals by Acanthaster planci infestation on reef fish communities at Iriomote Island, Japan. Mar Ecol Prog Ser 37:191-199

Sriver RL, Huber M (2007) Observational evidence for an ocean heat pump induced by tropical cyclones. Nature 447:577-580

Stewart BD, Jones GP (2001) Associations between the abundance of piscivorous fishes and their prey on coral reefs: implications for prey-fish mortality. Mar Biol (Berl) 138: 383-397

Sweatman HPA (1985) The influence of adults of some coral reef fishes on larval recruitment. Ecol Monogr 55: $469-485$

Sweatman H, Cheal A, Coleman C, Jonker M and others (2008) Long-term monitoring of the Great Barrier Reef. Status Report No. 8, Australian Institute of Marine Science, Townsville

Syms C, Jones GP (2000) Disturbance, habitat structure, and the dynamics of a coral-reef fish community. Ecology 81 : 2714-2729

- Thompson AA, Mapstone BD (1997) Intra- versus inter-annual variation in counts of reef fishes and interpretations of long-term monitoring studies. Mar Ecol Prog Ser 154: 53-63

Warwick RM, Clarke KR (1998) Taxonomic distinctness and environmental assessment. J Appl Ecol 35:532-543

Wilkinson C (2004) Status of coral reefs of the world: 2004, Vol 1. Australian Institute of Marine Science, Townsville

Wilkinson C, Souter D (2008) Status of Caribbean coral reefs after bleaching and hurricanes in 2005. Global Coral Reef Monitoring Network, and Reef and Rainforest Research Centre, Townsville

Williams ID, Polunin NVC, Hendrick VJ (2001) Limits to grazing by herbivorous fishes and the impact of low coral cover on macroalgal abundance on a coral reef in Belize. Mar Ecol Prog Ser 222:187-196

Wilson SK, Bellwood DR, Choat JH, Furnas MJ (2003) Detritus in the epilithic algal matrix and its use by coral reef fishes. Oceanogr Mar Biol Annu Rev 41:279-309

Wilson SK, Graham NAJ, Pratchett MS, Jones GP, Polunin NVC (2006) Multiple disturbances and the global degradation of coral reefs: Are reef fishes at risk or resilient? Glob Change Biol 12:2220-2234

> Wilson SK, Burgess SC, Cheal AJ, Emslie M and others (2008) Habitat utilization by coral reef fish: implications for specialists vs. generalists in a changing environment. J Anim Ecol 77:220-228

Worm B, Barbier EB, Beaumont N, Duffy JE and others (2006) Impacts of biodiversity loss on ocean ecosystem services. Science 314:787-790

Submitted: April 10, 2008; Accepted: August 24, 2008 Proofs received from author(s): November 17, 2008 